\title{
OPEN Effects of interdialytic interval on heart rate variability in chronic hemodialysis patients: a cross-sectional study
}

\author{
Kajohnsak Noppakun ${ }^{1,2}$, Phasakorn Putchagarn ${ }^{3}$, Arintaya Phrommintikul ${ }^{3}$ \& \\ Wanwarang Wongcharoen ${ }^{3 凶}$
}

Previous studies showed that long interdialytic interval of chronic hemodialysis increased risk of sudden cardiac death compared to short interdialytic interval. Diabetes mellitus (DM) and autonomic dysfunction are the strong adverse predictors of survival in ESRD patients. We aimed to compare autonomic function between long and short interdialytic interval of chronic hemodialysis in patients with and without DM. One-hundred sixty-three patients receiving chronic hemodialysis were enrolled. The electrocardiogram recording was performed twice in each patient during 4-h hemodialysis session after long and short interdialytic intervals to assess heart rate variability (HRV). Mean age was $61.4 \pm 14.3$ years. HRV parameters during hemodialysis did not differ between long and short interdialytic interval in overall population. Nevertheless, in $82(50.3 \%)$ patients, SDNN (47.4 \pm 23.8 vs. $43.4 \pm 19.5 \mathrm{~ms}, \mathrm{P}=0.039)$, ASDNN ( $24.8 \pm 14.3$ vs. $22.7 \pm 12.3 \mathrm{~ms}, \mathrm{P}=0.025), \mathrm{LF}(8.4 \pm 6.8$ vs. $7.6 \pm 6.6$ $\mathrm{ms}^{2}, P=0.040$ ) increased after long interdialytic interval. The greater change of SDNN, ASDNN, VLF and LF between long and short interdialytic intervals was noted in DM, compared to non-DM patients. We demonstrated that there was no difference of HRV parameters after short and long interdialytic interval. However, there was greater autonomic alteration observed in DM than non-DM patients between 2 interdialytic intervals.

Cardiovascular diseases are the leading cause of death in patients with end-stage kidney disease (ESRD) requiring chronic dialysis. Previous studies have demonstrated that sudden cardiac death (SCD) accounts for approximately $25 \%$ of all-cause mortality and $70 \%$ of cardiovascular mortality in patients with ESRD ${ }^{1-3}$. Conventionally, hemodialysis therapy is scheduled thrice weekly, or even twice weekly in some patients who still have residual renal function ${ }^{4}$. Interestingly, the higher mortality and incidence of SCD has been reported to occur during the long interdialytic interval compared to the short interdialytic interva ${ }^{5-7}$. It has been described that numerous factors contribute to the heightened risk of SCD in chronic hemodialysis patients. Chronic hypervolemia in patients receiving hemodialysis may result in the structural and functional changes in myocardium, leading to the occurrence of arrhythmia. The oxidative stress, inflammation and abnormal calcium or phosphate metabolism, may accelerate the progression of atherosclerosis, leading to the increased risk of myocardial infarction ${ }^{8,9}$. In addition, electrolyte imbalance and the disorder in autonomic nervous system may result in the increased risk of SCD ${ }^{10,11}$.

Heart rate variability (HRV) has been used to assess the autonomic function in several conditions including patients with ESRD. Several investigators have demonstrated that HRV predicts long-term cardiovascular outcomes in patients receiving chronic hemodialysis ${ }^{12-15}$. Nevertheless, little is known regarding the effect of long and short interdialytic interval on HRV patients with chronic hemodialysis. As the long interdialytic interval is associated with increased risk of SCD, it is possible that HRV may differ between long and short interdialytic interval. The presence of diabetes mellitus (DM) is a strong predictor of adverse prognosis in ESRD patients. It is well-established that DM is associated with overall decrease in $\mathrm{HRV}^{16}$. However, one study showed that HRV could not predict the outcomes in ESRD with diabetes mellitus (DM) ${ }^{14}$.

\footnotetext{
${ }^{1}$ Division of Nephrology, Department of Internal Medicine, Faculty of Medicine, Chiang Mai University, Chiang Mai, Thailand. ${ }^{2}$ Pharmacoepidemiology and Statistics Research Center (PESRC), Faculty of Pharmacy, Chiang Mai University, Chiang Mai, Thailand. ${ }^{3}$ Division of Cardiology, Department of Internal Medicine, Faculty of Medicine, Chiang Mai University, Chiang Mai 50200, Thailand. ${ }^{\circledR}$ email: bwanwarang@yahoo.com
} 
Therefore, we aimed to examine the difference of HRV parameters between the long interdialytic interval and short interdialytic interval in chronic hemodialysis patients and to compare the change of HRV between $\mathrm{DM}$ and non-DM patients.

\section{Methods}

Study design and participants. We conducted a cross-sectional study to explore the relationship between HRV and dialytic interval with DM status as an effect modifier. We enrolled ESRD patients who had been receiving regular hemodialysis at hemodialysis unit, Chiang Mai University hospital, between April 2018 to December 2018. Patients who were older than 18 years and received regular hemodialysis for at least 3 months were eligible to enroll into the study. Patients were excluded if they had atrial fibrillation, atrial flutter or pacemaker installation. All subjects underwent Holter ECG monitoring for HRV assessment (GE Seer Light Extend, GE Medical Systems, Suzuken Company, Ltd.) The Holter ECG was monitored twice for $4 \mathrm{~h}$ during dialysis session on the day after short interdialytic interval and on the day after long interdialytic interval. All patients enrolled in the study had been receiving thrice weekly hemodialysis. The long interdialytic interval was 2-day interval between hemodialysis sessions and the short interdialytic interval was 1-day interval between hemodialysis sessions.

Clinical data were obtained from medical records including age, gender, co-morbidities, medications, duration of hemodialysis, biochemical analysis and ultrafiltration volume. Baseline DM status was determined by self-report, documented DM from medical record, and history of using or currently use of diabetic medications or insulin.

The study procedure was performed according to Declaration of Helsinki. Informed consent was obtained from all participants. This study was approved by the ethics committee of the Faculty of Medicine, Chiang Mai University, approval number $108 / 2561$. It was registered in clinicaltrials.in.th, and the identification number is TCTR20180330002 (29 MAR 2018).

HRV measurement. Before analyzing the data, the ECG recordings were manually preprocessed to exclude noise and other artifacts. Premature supraventricular and ventricular beats, missed beats, and pauses were filtered and replaced by an interpolated value.

Time-domain and frequency-domain analyses were performed according to the standard guidelines ${ }^{17}$. Timedomain HRV indexes were analyzed using statistical methods. The square root of the mean squared differences of successive normal-to-normal (NN) intervals (rMSSD), the standard deviation (SD) of all NN intervals (SDNN), the average of the SD of the 5-min NN intervals over the entire recording (ASDNN), the SD of the average NN intervals calculated over 5-min periods of the entire recording (SDANN), and the proportion of adjacent NN intervals differing by $>50 \mathrm{~ms}$ (pNN50) during the 10-min recording were measured. Frequency-domain HRV were analyzed using autoregressive power spectral analysis applied to the RR interval time series. The order of the autoregressive models used to estimate the power spectrum was calculated by commercially available software (MARS $^{\mathrm{Tx}}$ Ambulatory ECG System software version 8, developed by GE Healthcare).

The following spectral bands were identified: very low frequency (VLF) $(0.003-0.04 \mathrm{~Hz})$, low frequency (LF) $(0.04-0.15 \mathrm{~Hz})$ and high frequency $(\mathrm{HF})(0.15-0.4 \mathrm{~Hz})$. Total power $(0-0.5 \mathrm{~Hz})$ and the areas below each peak was calculated in absolute units $\left(\mathrm{ms}^{2}\right)$. The normalization of LF (LF n.u.) and HF (HF n.u.) was also calculated in percentage. LF n.u. was defined as LF/ (total power-VLF) $\times 100$. HF n.u. was defined as HF/ (total power-VLF) $\times 100$. The absolute delta change of HRV parameters after long interdialytic interval and short interdialytic interval was defined as HRV parameters after long interdialytic interval-HRV parameters after short interdialytic interval.

Statistical analysis. Results were expressed as mean \pm SD, unless otherwise specified. The KolmogorovSmirnov test was used to assess normality of the data. The continuous variables were compared between groups with the paired or unpaired t test as appropriate. Mann-Whitney $U$ test and Wilcoxon signed-rank test were used if data were not normally distributed. Categorical variables were summarized using frequencies and proportions and were compared using Chi-square or Fischer exact test as appropriate. $\mathrm{P}$ values $<0.05$ were considered statistically significant. Statistical software package IBM SPSS Statistics for Windows, version 23.0 (IBM Corp., Armonk, NY, USA, https://www.ibm.com/products/spss-statistics) was used for analysis.

Ethics approval and consent to participate. The study was registered in clinicaltrials.in.th, and the identification number is TCTR20180330002. The Effect of long and short interdialytic interval of chronic hemodialysis on heart rate variability in patients with ESRD was approved by the ethics committee of the Faculty of Medicine, Chiang Mai University, approval number 108/2561. The investigations were performed according to Declaration of Helsinki. Informed consent was obtained from all participants.

\section{Results}

Baseline characteristics. One-hundred sixty-three patients with ESRD receiving regular hemodialysis were enrolled in the study. Baseline clinical characteristics and biochemical data are shown in Table 1. The mean age of overall population was $61.4 \pm 14.3$ years. The mean left ventricular ejection fraction of $63.0 \pm 12.3 \%$. The median dialysis vintage was $3(1-5)$ years. The primary cause of ESRD in nearly half of the patients (48.6\%) was diabetic nephropathy. Other causes included glomerulonephritis (15.9\%) and hypertensive nephropathy (15.2\%). All patients had been receiving thrice weekly hemodialysis. Of 163 patients, 82 (50.3\%) had DM and 81 (49.7\%) did not have DM at baseline. Compared between DM and non-DM patients, DM patients are older $(63.8 \pm 10.4$ vs. $58.9 \pm 17.1, \mathrm{P}=0.025)$ and had higher prevalence of dyslipidemia. DM patients also had greater use of antiplatelet agents, statins and diuretics. 


\begin{tabular}{|c|c|c|c|c|}
\hline & Total $(\mathrm{N}=163)$ & $\mathrm{DM}(\mathrm{N}=82)$ & Non-DM $(\mathrm{N}=\mathbf{8 1})$ & P value ${ }^{a}$ \\
\hline Age (years) & $61.4 \pm 14.3$ & $63.8 \pm 10.4$ & $58.9 \pm 17.1$ & 0.025 \\
\hline Male & $88(54.0 \%)$ & $57(59.4 \%)$ & $52(50.0 \%)$ & 0.203 \\
\hline Dialysis vintage ${ }^{\mathrm{b}}$ (years) & $3(1-5)$ & $3(1-5)$ & $4(1-7)$ & 0.057 \\
\hline LVEF (\%) & $63.0 \pm 12.3$ & $62.5 \pm 13.1$ & $63.5 \pm 11.4$ & 0.927 \\
\hline $\mathrm{Kt} / \mathrm{V}$ & $1.7 \pm 0.3$ & $1.6 \pm 0.3$ & $1.7 \pm 0.3$ & 0.314 \\
\hline Albumin $(\mathrm{g} / \mathrm{dL})$ & $3.9 \pm 0.4$ & $4.0 \pm 0.4$ & $3.9 \pm 0.5$ & 0.149 \\
\hline Hemoglobin $(\mathrm{g} / \mathrm{dL})$ & $10.5 \pm 1.7$ & $10.7 \pm 1.6$ & $10.3 \pm 1.8$ & 0.226 \\
\hline \multicolumn{5}{|l|}{ Co-morbidities } \\
\hline Hypertension & $151(94.4 \%)$ & $76(93.8 \%)$ & $75(94.9 \%)$ & 1.000 \\
\hline Dyslipidemia & $111(70.3 \%)$ & $71(88.8 \%)$ & $40(51.3 \%)$ & $<0.001$ \\
\hline Coronary artery disease & $24(15.2 \%)$ & $16(20.0 \%)$ & $8(10.3 \%)$ & 0.120 \\
\hline Cardiovascular disease & $12(7.6 \%)$ & $6(7.5 \%)$ & $6(7.7 \%)$ & 1.000 \\
\hline Peripheral artery disease & $4(2.5 \%)$ & $3(3.8 \%)$ & $1(1.3 \%)$ & 0.620 \\
\hline Chronic obstructive pulmonary disease & $3(1.9 \%)$ & $1(1.3 \%)$ & $2(2.6 \%)$ & 0.618 \\
\hline \multicolumn{5}{|l|}{ Medications } \\
\hline ACEI/ARB & $56(35.7 \%)$ & $26(32.9 \%)$ & $30(38.5 \%)$ & 0.508 \\
\hline Beta-blockers & $104(66.2 \%)$ & $53(67.1 \%)$ & $51(65.4 \%)$ & 0.867 \\
\hline Calcium channel blockers & $117(74.5 \%)$ & $56(70.9 \%)$ & $61(78.2 \%)$ & 0.360 \\
\hline Diuretics & $75(47.8 \%)$ & $52(65.8 \%)$ & $23(29.5 \%)$ & $<0.001$ \\
\hline Alpha blockers & $52(33.1 \%)$ & $28(35.4 \%)$ & $24(30.8 \%)$ & 0.612 \\
\hline Statins & $107(68.2 \%)$ & $65(82.3 \%)$ & $42(53.8 \%)$ & $<0.001$ \\
\hline Anti-platelets & $60(38.2 \%)$ & $48(60.8 \%)$ & $12(15.4 \%)$ & $<0.001$ \\
\hline Oral anticoagulants & $11(7.0 \%)$ & $6(7.6 \%)$ & $5(6.4 \%)$ & 1.000 \\
\hline
\end{tabular}

Table 1. Baseline characteristics. $A C E I / A R B$ angiotensin converting enzyme inhibitor/angiotensin receptor blocker, $D M$ diabetes mellitus, $L V E F$ left ventricular ejection fraction. ${ }^{a} \mathrm{P}$ value from the comparisons between $\mathrm{DM}$ versus non-DM using unpaired $\mathrm{t}$ test or Chi-square test unless otherwise specified. ${ }^{\mathrm{b}}$ Median (interquartile range) and were compared between groups using Mann-Whitney $\mathrm{U}$ test.

Clinical and biochemical data between short and long interdialytic intervals. The interdialytic weigh gain was greater after long interdialytic interval than that after short interdialytic interval $(2.2 \pm 1.0$ vs. $1.7 \pm 1.0 \mathrm{~kg}, \mathrm{P}<0.001)$. The fluid removal volume was also greater after long interdialytic interval than that after short interdialytic interval $(2,411 \pm 1,015$ vs. $2,005 \pm 950 \mathrm{~mL}, \mathrm{P}<0.001)$. There was no difference of blood pressure prior hemodialysis when measured on the day after long interdialytic interval and after short interdialytic interval. We did not observe the increase in serum potassium after long interdialytic interval compared to that after short interdialytic interval. On the contrary, we found that serum potassium was lower after long interdialytic interval compared to short interdialytic interval in $\mathrm{DM}$ patients $(4.3 \pm 0.6$ vs. $4.4 \pm 0.6, \mathrm{P}=0.03)$. No difference of serum potassium was noted after long and short interdialytic intervals in non-DM patients. (Table 2).

The HRV after long interdialytic interval and short interdialytic interval. Table 3 shows the comparison of HRV during 4-h hemodialysis between short and long interdialytic interval in overall population. We demonstrated that all HRV parameters did not differ between short and long interdialytic interval.

The change of HRV parameters after long and short interdialytic intervals were analyzed according to diabetic status. (Table 4) In 81 non-DM patients, there were no differences of time-domain and frequency-domain HRV parameters between long and short interdialytic intervals. However, in $82(50.3 \%)$ DM patients, SDNN ( $47.4 \pm 23.8 \mathrm{~ms}$ vs. $43.4 \pm 19.5 \mathrm{~ms}, \mathrm{P}=0.039)$, ASDNN ( $24.8 \pm 14.3 \mathrm{~ms}$ vs. $22.7 \pm 12.3 \mathrm{~ms}, \mathrm{P}=0.025), \mathrm{LF}(8.4 \pm 6.8$ $\mathrm{ms}^{2}$ vs. $\left.7.6 \pm 6.6 \mathrm{~ms}^{2}, \mathrm{P}=0.040\right)$ increased after long interdialytic interval. Nevertheless, there was no difference in LF n.u., HF n.u. and LF/HF ratio between 2 intervals.

The absolute delta change of HRV parameters after long and short interdialytic intervals was compared between DM and non-DM patients. (Table 5) We demonstrated the greater increment of SDNN $(+4.0 \pm 17.1 \mathrm{~ms}$ vs. $-3.5 \pm 20.2 \mathrm{~ms}, \mathrm{P}=0.006)$, $\operatorname{ASDNN}(+2.1 \pm 8.1 \mathrm{~ms}$, vs. $-8.0 \pm 54.9 \mathrm{~ms}, \mathrm{p}=0.003)$, VLF $\left(+1.0 \pm 5.1 \mathrm{~ms}^{2}\right.$ vs. $\left.-0.7 \pm 7.7 \mathrm{~ms}^{2}, \mathrm{P}=0.040\right)$ and $\mathrm{LF}\left(+0.7 \pm 4.6 \mathrm{~ms}^{2} \mathrm{vs} .-0.6 \pm 9.0 \mathrm{~ms}^{2}, \mathrm{P}=0.040\right)$ after long interdialytic interval compared to short interdialytic interval in DM than non-DM patients.

\section{Discussion}

Sudden cardiac death has become a great concern in the management of patients with ESRD receiving chronic hemodialysis $^{1,2}$. It has been described that autonomic dysfunction plays an important role in the occurrence of $\mathrm{SCD}^{18}$. Previous study has demonstrated the sympathetic overactivity and vagal withdrawal in patients with ESRD receiving chronic hemodialysis. Furthermore, the investigators found that the autonomic dysfunction was associated with higher left ventricular mass and poorer physical performance in chronic hemodialysis patients ${ }^{19}$. 


\begin{tabular}{|c|c|c|c|c|c|c|c|c|c|}
\hline & \multicolumn{2}{|l|}{ Total $(\mathrm{N}=163)$} & \multirow[b]{2}{*}{ Pvalue ${ }^{a}$} & \multicolumn{2}{|c|}{$\mathrm{DM}(\mathrm{N}=\mathbf{8 2})$} & \multirow[b]{2}{*}{ P value ${ }^{a}$} & \multicolumn{2}{|l|}{ Non-DM $(\mathrm{N}=\mathbf{8 1})$} & \multirow[b]{2}{*}{ P value ${ }^{a}$} \\
\hline & $\begin{array}{l}\text { Short interdialytic } \\
\text { interval }\end{array}$ & $\begin{array}{l}\text { Long interdialytic } \\
\text { interval }\end{array}$ & & $\begin{array}{l}\text { Short interdialytic } \\
\text { interval }\end{array}$ & \begin{tabular}{|l|} 
Long interdialytic \\
interval
\end{tabular} & & $\begin{array}{l}\text { Short interdialytic } \\
\text { interval }\end{array}$ & $\begin{array}{l}\text { Long interdialytic } \\
\text { interval }\end{array}$ & \\
\hline $\begin{array}{l}\text { Interdialytic weight } \\
\text { gain }(\mathrm{kg})\end{array}$ & $1.7 \pm 1.0$ & $2.2 \pm 1.0$ & $<0.001$ & $1.8 \pm 1.0$ & $2.2 \pm 1.0$ & $<0.001$ & $1.7 \pm 1.0$ & $2.0 \pm 1.0$ & $<0.001$ \\
\hline $\begin{array}{l}\text { Net ultrafiltration } \\
(\mathrm{mL})\end{array}$ & $2005 \pm 950$ & $2411 \pm 1015$ & $<0.001$ & $2097 \pm 1000$ & $2529 \pm 1068$ & $<0.001$ & $1911 \pm 893$ & $2292 \pm 950$ & $<0.001$ \\
\hline $\begin{array}{l}\text { Pre-dialysis SBP } \\
(\mathrm{mmHg})\end{array}$ & $143 \pm 20$ & $146 \pm 20$ & 0.083 & $145 \pm 22$ & $147 \pm 21$ & 0.273 & $141 \pm 19$ & $144 \pm 19$ & 0.181 \\
\hline $\begin{array}{l}\text { Pre-dialysis DBP } \\
(\mathrm{mmHg})\end{array}$ & $74 \pm 13$ & $75 \pm 13$ & 0.685 & $71 \pm 12$ & $72 \pm 13$ & 0.689 & $77 \pm 13$ & $78 \pm 14$ & 0.856 \\
\hline $\begin{array}{l}\text { Post-dialysis SBP } \\
(\mathrm{mmHg})\end{array}$ & $143 \pm 18$ & $145 \pm 18$ & 0.201 & $140 \pm 17$ & $145 \pm 19$ & 0.022 & $146 \pm 19$ & $145 \pm 17$ & 0.689 \\
\hline $\begin{array}{l}\text { Post-dialysis DBP } \\
(\mathrm{mmHg})\end{array}$ & $77 \pm 12$ & $77 \pm 12$ & 0.936 & $72 \pm 10$ & $73 \pm 11$ & 0.114 & $82 \pm 11$ & $80 \pm 12$ & 0.256 \\
\hline $\begin{array}{l}\text { Pre-dialysis serum } \\
\text { sodium (mmol/L) }\end{array}$ & $137 \pm 3$ & $137 \pm 3$ & 0.077 & $137 \pm 3$ & $136 \pm 3$ & 0.126 & $138 \pm 3$ & $138 \pm 3$ & 0.337 \\
\hline $\begin{array}{l}\text { Pre-dialysis } \\
\text { serum potassium } \\
(\mathrm{mmol} / \mathrm{L})\end{array}$ & $4.4 \pm 0.6$ & $4.3 \pm 0.6$ & 0.125 & $4.4 \pm 0.6$ & $4.3 \pm 0.6$ & 0.029 & $4.4 \pm 0.6$ & $4.4 \pm 0.7$ & 0.686 \\
\hline
\end{tabular}

Table 2. The clinical and biochemical data between short and long interdialytic intervals in patients with and without diabetes mellitus. $D B P$ diastolic blood pressure, $D M$ diabetes mellitus, $S B P$ systolic blood pressure. ${ }^{\text {aP }}$ value from the comparisons between short versus long interdialytic interval using paired $\mathrm{t}$ test.

\begin{tabular}{|l|c|l|l|}
\hline \multirow{2}{*}{ HRV parameters } & \multicolumn{2}{|l|}{ Total (N=163) } & \multirow{2}{*}{ P value* } \\
\cline { 2 - 4 } & Short interdialytic interval & Long interdialytic interval & \multirow{2}{*}{ P } \\
\hline Mean NN (ms) & $869.8 \pm 136.0$ & $864.8 \pm 132.8$ & 0.369 \\
\hline SDNN (ms) & $49.1 \pm 21.5$ & $49.3 \pm 23.7$ & 0.946 \\
\hline SDANN (ms) & $40.0 \pm 18.1$ & $38.6 \pm 19.9$ & 0.714 \\
\hline rMSSD (ms) & $21.2 \pm 16.8$ & $22.3 \pm 24.1$ & 0.805 \\
\hline pNN50 (\%) & $4.6 \pm 10.1$ & $4.2 \pm 8.5$ & 0.952 \\
\hline VLF (ms $\left.{ }^{2}\right)$ & $15.4 \pm 8.3$ & $15.6 \pm 9.0$ & 0.916 \\
\hline LF (ms $\left.{ }^{2}\right)$ & $9.9 \pm 7.8$ & $10.0 \pm 8.0$ & 0.756 \\
\hline LF normalized unit (n.u.) & $51.9 \pm 10.8$ & $52.5 \pm 10.8$ & 0.381 \\
\hline HF (ms $\left.{ }^{2}\right)$ & $8.6 \pm 6.5$ & $8.5 \pm 6.1$ & 0.960 \\
\hline HF normalized unit (n.u.) & $48.1 \pm 10.8$ & $47.5 \pm 10.8$ & 0.381 \\
\hline LF/HF ratio & $1.2 \pm 0.5$ & $1.2 \pm 0.5$ & 0.681 \\
\hline
\end{tabular}

Table 3. Heart rate variability during 4-h hemodialysis between short and long interdialytic interval in overall population. ${ }^{\star} \mathrm{P}<0.05$ from the comparison between short interdialytic interval and long interdialytic interval using unpaired.

Several observational studies have shown that the incidence of SCD significantly increased during the period after long interdialytic interval compared to that after short interdialytic interval ${ }^{5,6}$. The significant alteration of fluid and electrolytes fluxes may account for the worse outcomes after long interdialytic interval. In addition, the acid-base imbalance and the change in left ventricular mechanics may contribute to the heightened risk after long interdialytic interval. It is possible that these alterations after long interdialytic interval may result in the change of autonomic function, leading to the increased risk of SCD during the period after long interdialytic interval. Several investigators have reported that HRV predicts long-term outcomes in ESRD patients receiving hemodialysis ${ }^{12-14}$.

In this study, we observed that there was no difference of HRV parameters after short and long interdialytic interval in overall population. With this regard, the contribution of autonomic dysfunction to the increased risk of SCD after long interdialytic interval may be relatively low, compared to other strong risk factors ${ }^{20}$.

The autonomic dysfunction is highly prevalent in DM patients ${ }^{16}$. The decrease in overall HRV has been described in patients with DM and is associated with poor prognosis ${ }^{21}$. Therefore, we also analyzed HRV parameters according to diabetic status. We demonstrated that HRV parameters were comparable between the periods after long and short interdialytic intervals in non-DM patients. Nevertheless, in DM patients, the greater increment in SDNN, ASDNN, VLF and LF was evident after long interdialytic interval than after short interdialytic interval. It is plausible that the autonomic dysfunction in DM patients may account for the greater difference of HRV parameters between long and short interdialytic interval than non-DM patients ${ }^{22}$. Previous studies suggest that VLF is influenced by the renin-angiotensin system and is also associated with the sympathetic activity ${ }^{23-26}$. LF reflects both sympathetic activity and vagal activity. Several investigators have described that the increase in 


\begin{tabular}{|c|c|c|c|c|c|c|}
\hline \multirow[b]{2}{*}{ HRV parameters } & \multicolumn{2}{|l|}{ DM patients $(\mathrm{N}=82)$} & \multirow[b]{2}{*}{ P value } & \multicolumn{2}{|c|}{ Non-DM patients $(\mathrm{N}=81)$} & \multirow[b]{2}{*}{ P value } \\
\hline & $\begin{array}{l}\text { Short interdialytic } \\
\text { interval }\end{array}$ & $\begin{array}{l}\text { Long interdialytic } \\
\text { interval }\end{array}$ & & $\begin{array}{l}\text { Short interdialytic } \\
\text { interval }\end{array}$ & $\begin{array}{l}\text { Long interdialytic } \\
\text { interval }\end{array}$ & \\
\hline Mean NN (ms) & $862 \pm 115$ & $852 \pm 116$ & 0.113 & $878 \pm 155$ & $878 \pm 147$ & 0.731 \\
\hline SDNN (ms) & $43.4 \pm 19.5$ & $47.4 \pm 23.8$ & $0.039^{*}$ & $54.8 \pm 22.0$ & $51.3 \pm 23.6$ & 0.059 \\
\hline SDANN (ms) & $34.9 \pm 16.7$ & $38.5 \pm 21.4$ & 0.125 & $41.0 \pm 19.0$ & $38.7 \pm 18.4$ & 0.291 \\
\hline ASDNN (ms) & $22.7 \pm 12.3$ & $24.8 \pm 14.3$ & $0.025^{*}$ & $39.2 \pm 59.3$ & $31.2 \pm 15.7$ & 0.051 \\
\hline $\mathrm{rMSSD}(\mathrm{ms})$ & $18.3 \pm 14.6$ & $22.4 \pm 31.3$ & 0.338 & $24.2 \pm 18.3$ & $22.1 \pm 13.6$ & 0.238 \\
\hline pNN50 (\%) & $3.5 \pm 8.9$ & $4.3 \pm 9.6$ & 0.239 & $5.4 \pm 11.1$ & $4.2 \pm 7.3$ & 0.280 \\
\hline $\operatorname{VLF}\left(\mathrm{ms}^{2}\right)$ & $12.5 \pm 7.2$ & $13.5 \pm 8.5$ & 0.153 & $18.4 \pm 8.4$ & $17.7 \pm 9.0$ & 0.174 \\
\hline $\mathrm{LF}\left(\mathrm{ms}^{2}\right)$ & $7.6 \pm 6.6$ & $8.4 \pm 6.8$ & $0.040^{*}$ & $12.3 \pm 8.2$ & $11.7 \pm 8.8$ & 0.210 \\
\hline $\begin{array}{l}\text { LF normalized unit } \\
\text { (n.u.) }\end{array}$ & $49.9 \pm 10.0$ & $51.1 \pm 11.9$ & 0.297 & $53.8 \pm 10.3$ & $54.0 \pm 9.3$ & 0.968 \\
\hline $\mathrm{HF}\left(\mathrm{ms}^{2}\right)$ & $7.2 \pm 5.7$ & $7.5 \pm 5.8$ & 0.299 & $10.1 \pm 6.8$ & $9.5 \pm 6.2$ & 0.398 \\
\hline $\begin{array}{l}\text { HF normalized unit } \\
\text { (n.u.) }\end{array}$ & $50.0 \pm 11.0$ & $48.9 \pm 11.9$ & 0.297 & $46.1 \pm 10.3$ & $46.0 \pm 9.3$ & 0.968 \\
\hline LF/HF ratio & $1.1 \pm 0.5$ & $1.1 \pm 0.5$ & 0.486 & $1.3 \pm 0.4$ & $1.3 \pm 0.5$ & 0.908 \\
\hline
\end{tabular}

Table 4. Heart rate variability between short and long interdialytic interval, according to diabetic status. ${ }^{\star} \mathrm{P}$ value from the comparison between short versus long interdialytic interval using paired t test.

\begin{tabular}{|l|l|l|l|}
\hline$\Delta$ HRV parameters & DM patients $(\mathbf{N}=\mathbf{8 2})$ & Non-DM patients $(\mathbf{N}=\mathbf{8 1})$ & P value $^{*}$ \\
\hline$\Delta$ SDNN $(\mathrm{ms})$ & $+4.0 \pm 17.1$ & $-3.5 \pm 20.2$ & 0.006 \\
\hline$\Delta$ SDANN $(\mathrm{ms})$ & $+3.6 \pm 18.3$ & $-2.3 \pm 18.3$ & 0.075 \\
\hline$\Delta$ ASDNN $(\mathrm{ms})$ & $+2.1 \pm 8.2$ & $-8.0 \pm 54.9$ & 0.003 \\
\hline$\Delta$ rMSSD $(\mathrm{ms})$ & $+4.2 \pm 28.9$ & $-2.1 \pm 14.7$ & 0.125 \\
\hline$\Delta$ pNN50 $\%)$ & $+0.8 \pm 7.1$ & $-1.2 \pm 10.5$ & 0.100 \\
\hline$\Delta$ VLF $\left(\mathrm{ms}^{2}\right)$ & $+1.0 \pm 5.1$ & $-0.7 \pm 7.7$ & 0.040 \\
\hline$\Delta$ LF $\left(\mathrm{ms}^{2}\right)$ & $+0.7 \pm 4.6$ & $-0.6 \pm 9.0$ & 0.040 \\
\hline$\Delta$ LF normalized unit (n.u.) & $+1.1 \pm 7.8$ & $+0.1 \pm 8.6$ & 0.418 \\
\hline$\Delta$ HF $\left(\mathrm{ms}^{2}\right)$ & $+0.3 \pm 3.9$ & $-0.6 \pm 6.0$ & 0.189 \\
\hline$\Delta$ HF normalized unit (n.u.) & $-1.1 \pm 7.8$ & $-0.1 \pm 8.6$ & 0.418 \\
\hline$\Delta$ LF/HF ratio & $0 \pm 0.4$ & $0 \pm 0.4$ & 0.582 \\
\hline
\end{tabular}

Table 5. The change of HRV parameters between long and short interdialytic intervals, compared between DM and non-DM patients. $\Delta=$ absolute change of HRV parameters between long and short interdialytic intervals, $D M$ diabetes mellitus, $H R V$ heart rate variability. ${ }^{\star} \mathrm{P}$ value from the comparison between $\mathrm{DM}$ and non-DM patients using unpaired t test.

LF may indicate the increased sympathetic activity ${ }^{23,27}$. As a result, the activity of renin-angiotensin system and sympathetic system may increase after long interdialytic interval compared to short interdialytic interval in DM patients. Whether these changes in HRV parameters can explain the increased risk of SCD after long interdialytic interval in DM patients merits further study.

This study has some limitations. It is a single center study although the number of participants in the study is relatively large. Regarding the generalizability of our study, the studied participants had baseline characteristics as well as concomitant medications including beta-blockers which were comparable to other studies ${ }^{7,28}$. Therefore, we expect that our results can be applied to other populations. Lastly, we did not adjust P-values for multiple statistical testing in our study as this measure may increase the chance of making a type II error ${ }^{29}$. The quality and an effect size of our study should be considered in accordance with an interpretation of statistical significance.

\section{Conclusion}

We demonstrated that there was no difference of HRV parameters after short and long interdialytic interval. According to diabetic status, there was greater autonomic alteration observed in DM patients between short and long interdialytic intervals than in non-DM patients.

\section{Data availability}

The informed consent given by effect of long and short interdialytic interval of chronic hemodialysis on heart rate variability in patients with ESRD study participants does not cover data posting in public databases. However, data are available upon request should be sent to bwanwarang@yahoo.com and are subject to approval by the Faculty of Medicine, Chiang Mai University Ethics Committee. 
Received: 11 March 2021; Accepted: 27 September 2021

Published online: 22 October 2021

\section{References}

1. Bleyer, A. J. et al. Characteristics of sudden death in hemodialysis patients. Kidney Int. 69, 2268-2273. https://doi.org/10.1038/sj. ki.5000446 (2006).

2. Bleyer, A. J., Russell, G. B. \& Satko, S. G. Sudden and cardiac death rates in hemodialysis patients. Kidney Int. 55, 1553-1559. https://doi.org/10.1046/j.1523-1755.1999.00391.x (1999).

3. Zachariah, D., Kalra, P. R. \& Roberts, P. R. Sudden cardiac death in end stage renal disease: Unlocking the mystery. J. Nephrol. 28, 133-141. https://doi.org/10.1007/s40620-014-0151-3 (2015).

4. Kalantar-Zadeh, K. et al. Twice-weekly and incremental hemodialysis treatment for initiation of kidney replacement therapy. Am. J. Kidney Dis. 64, 181-186. https://doi.org/10.1053/j.ajkd.2014.04.019 (2014).

5. Foley, R. N., Gilbertson, D. T., Murray, T. \& Collins, A. J. Long interdialytic interval and mortality among patients receiving hemodialysis. N. Engl. J. Med. 365, 1099-1107. https://doi.org/10.1056/NEJMoa1103313 (2011).

6. Wong, M. C. et al. Temporal distribution of arrhythmic events in chronic kidney disease: Highest incidence in the long interdialytic period. Heart Rhythm 12, 2047-2055. https://doi.org/10.1016/j.hrthm.2015.06.033 (2015).

7. Fotheringham, J. et al. The association between longer haemodialysis treatment times and hospitalization and mortality after the two-day break in individuals receiving three times a week haemodialysis. Nephrol. Dial. Transplant. 34, 1577-1584. https://doi. org/10.1093/ndt/gfz007 (2019).

8. Dohi, Y. et al. Candesartan reduces oxidative stress and inflammation in patients with essential hypertension. Hypertens. Res. 26, 691-697 (2003).

9. Lee, M. J. et al. Interdialytic weight gain and cardiovascular outcome in incident hemodialysis patients. Am. J. Nephrol. 39, 427-435. https://doi.org/10.1159/000362743 (2014).

10. Makar, M. S. \& Pun, P. H. Sudden cardiac death among hemodialysis patients. Am. J. Kidney Dis. 69, 684-695. https://doi.org/10. 1053/j.ajkd.2016.12.006 (2017)

11. Brunelli, S. M., Du Mond, C., Oestreicher, N., Rakov, V. \& Spiegel, D. M. Serum potassium and short-term clinical outcomes among hemodialysis patients: Impact of the long interdialytic interval. Am. J. Kidney Dis. 70, 21-29. https://doi.org/10.1053/j.ajkd.2016. 10.024 (2017).

12. Huang, J. C. et al. Heart rate variability predicts major adverse cardiovascular events and hospitalization in maintenance hemodialysis patients. Kidney Blood Press. Res. 42, 76-88. https://doi.org/10.1159/000469716 (2017).

13. Huang, Y. T. et al. Heart rate variability during hemodialysis is an indicator for long-term vascular access survival in uremic patients. PLoS ONE 12, e0172212. https://doi.org/10.1371/journal.pone.0172212 (2017).

14. Kida, N. et al. Usefulness of measurement of heart rate variability by Holter ECG in hemodialysis patients. BMC Nephrol. 18, 8 . https://doi.org/10.1186/s12882-016-0423-3 (2017).

15. Poulikakos, D., Hnatkova, K., Banerjee, D. \& Malik, M. Association of QRS-T angle and heart rate variability with major cardiac events and mortality in hemodialysis patients. Ann. Noninvasive Electrocardiol. 23, e12570. https://doi.org/10.1111/anec.12570 (2018).

16. Benichou, T. et al. Heart rate variability in type 2 diabetes mellitus: A systematic review and meta-analysis. PLoS ONE 13, e0195166. https://doi.org/10.1371/journal.pone.0195166 (2018).

17. Heart rate variability: Standards of measurement, physiological interpretation and clinical use. Task Force of the European Society of Cardiology and the North American Society of Pacing and Electrophysiology. Circulation 93, 1043-1065 (1996).

18. Japundzic-Zigon, N. et al. Sudden death: Neurogenic causes, prediction and prevention. Eur. J. Prev. Cardiol. 25, 29-39. https:// doi.org/10.1177/2047487317736827 (2018).

19. Chan, C. T. et al. Determinants of cardiac autonomic dysfunction in ESRD. Clin. J. Am. Soc. Nephrol. 5, 1821-1827. https://doi. org/10.2215/CJN.03080410 (2010).

20. Sanguankeo, A. \& Upala, S. Metabolic syndrome increases mortality risk in dialysis patients: A systematic review and meta-analysis. Int. J. Endocrinol. Metab. 16, e61201. https://doi.org/10.5812/ijem.61201 (2018).

21. Bissinger, A. Cardiac autonomic neuropathy: Why should cardiologists care about that?. J. Diabetes Res. 2017, 5374176. https:// doi.org/10.1155/2017/5374176 (2017).

22. Chang, Y. M. et al. Impact of metabolic syndrome and its components on heart rate variability during hemodialysis: A crosssectional study. Cardiovasc. Diabetol. 15, 16. https://doi.org/10.1186/s12933-016-0328-2 (2016).

23. Ernst, G. Heart-rate variability-more than heart beats?. Front. Public Health 5, 240. https://doi.org/10.3389/fpubh.2017.00240 (2017).

24. Malliani, A., Pagani, M., Lombardi, F. \& Cerutti, S. Cardiovascular neural regulation explored in the frequency domain. Circulation 84, 482-492. https://doi.org/10.1161/01.cir.84.2.482 (1991).

25. Parati, G., Saul, J. P., Di Rienzo, M. \& Mancia, G. Spectral analysis of blood pressure and heart rate variability in evaluating cardiovascular regulation. A critical appraisal. Hypertension 25, 1276-1286. https://doi.org/10.1161/01.hyp.25.6.1276 (1995).

26. Taylor, J. A., Carr, D. L., Myers, C. W. \& Eckberg, D. L. Mechanisms underlying very-low-frequency RR-interval oscillations in humans. Circulation 98, 547-555. https://doi.org/10.1161/01.cir.98.6.547 (1998).

27. Burr, R. L. Interpretation of normalized spectral heart rate variability indices in sleep research: A critical review. Sleep 30, 913-919. https://doi.org/10.1093/sleep/30.7.913 (2007).

28. Rantanen, J. M. et al. Arrhythmias in patients on maintenance dialysis: A cross-sectional study. Am. J. Kidney Dis. 75, $214-224$. https://doi.org/10.1053/j.ajkd.2019.06.012 (2020).

29. Feise, R. J. Do multiple outcome measures require p-value adjustment?. BMC Med. Res. Methodol. 2, 8. https://doi.org/10.1186/ 1471-2288-2-8 (2002).

\section{Acknowledgements}

We would like to express our appreciation to all an effort and contribution the study support from Staffs in the Northern Dialysis Center and Division of Nephrology, Department of Internal Medicine, Faculty of Medicine, Chiang Mai University, Chiang Mai, Thailand.

\section{Author contributions}

K.N. performed the statistical analyses, evaluated the results and drafted the paper. P.P. recruited patients. A.P. and collected the data and contributed substantially to data preparation and quality assurance. W.W. designed study, participated in the conception and design of the study revised the paper for important intellectual content. All authors have read and approved the final manuscript. 


\section{Funding}

This work was supported by the Faculty of Medicine Endowment Fund for medical research, Chiang Mai University, Thailand (141/2561). The funder had no role in study design, data collection and analysis, decision to publish, or preparation of the manuscript.

\section{Competing interests}

The authors declare no competing interests.

\section{Additional information}

Correspondence and requests for materials should be addressed to W.W.

Reprints and permissions information is available at www.nature.com/reprints.

Publisher's note Springer Nature remains neutral with regard to jurisdictional claims in published maps and institutional affiliations.

(c) (i) Open Access This article is licensed under a Creative Commons Attribution 4.0 International License, which permits use, sharing, adaptation, distribution and reproduction in any medium or format, as long as you give appropriate credit to the original author(s) and the source, provide a link to the Creative Commons licence, and indicate if changes were made. The images or other third party material in this article are included in the article's Creative Commons licence, unless indicated otherwise in a credit line to the material. If material is not included in the article's Creative Commons licence and your intended use is not permitted by statutory regulation or exceeds the permitted use, you will need to obtain permission directly from the copyright holder. To view a copy of this licence, visit http://creativecommons.org/licenses/by/4.0/.

(c) The Author(s) 2021 